\title{
Relato de intervenção nutricional pautada no Modelo Transteórico em indivíduos com excesso de peso em uma unidade de saúde da família de Palmas/TO
}

\author{
Kíllya de Paiva Santos, Alinne Aurélio Carneiro, Graziela Ramirez de Figueiredo, Gabriela de \\ Campos Mendes, Marília Marilourdes Mendes Lima, Renata Andrade de Medeiros Moreira
}

\begin{abstract}
Resumo
O Modelo Transteórico (MT) classifica os indivíduos em estágios de comportamento alimentar, direcionando a elaboração de intervenções segundo as características de cada um. Dessa forma, espera-se que a mudança de comportamento ocorra de forma graudal, atendendo o processo cognitivo-comportamental dos estágios. Relatar implementação das intervenções nutricionais segundo Modelo Transteórico realizadas com usuários com excesso de peso de uma Unidade de Saúde da Família (USF) de Palmas. Pesquisa integrante da segunda etapa do estudo de intervenção "Mudança de estágios de comportamento alimentar segundo Modelo Transteórico em indivíduos com excesso de peso em uma Unidade Básica de Saúde do Plano Diretor Sul de Palmas/Tocantins". Foi realizada intervenção nutricional com os 28 usuários com excesso de peso das duas equipes de uma USF que participavam de grupos. Esses foram classificados nos estágios de comportamento alimentar (Sutton et al, 2003) quanto a 4 comportamentos-alvo (óleos e gorduras; porções; frutas, legumes e verduras-FLV; e exercício físico), subdividindo-os em Grupo Pré-Ação (GPA): précontemplação, contemplação e decisão; e Grupo Ação (GA): ação e manutenção. As intervenções ocorreram entre agosto e outubro de 2015, sendo desenvolvida uma intervenção de cada comportamento-alvo em cada grupo. Realizou-se sensibilização dos usuários para a participação nas oficinas, que aconteceram uma vez/semana por grupo com duração de 50 minutos, desenvolvendo acolhimento, aplicação de pré-teste, apresentação da proposta do dia, execução da atividade lúdica, espaço para perguntas e dúvidas, e aplicação de pós-teste. A pesquisa foi aprovada pelo Comitê de Ética do Centro Universitário Luterano de Palmas (694.586/2014) e assinou-se o Termo de Consentimento Livre e Esclarecido. Dos usuários 92,9\% eram mulheres com idade média de 56,0 $\pm 15,0$ anos. Pelo MT 64,3\% dos indivíduos estavam no GPA para porções, 78,6\% para óleos e gorduras, 85,7\% para FLV e exercício físico. No GPA trabalhou-se: Óleos e Gorduras (tipos e qualidades de gorduras consumidas); Porções (conceito de porção de alimentos variados); FLV (compra de hortifruti com preços reais do comércio local); e Exercício Físico (prática da atividade física melhorando a qualidade de vida). No GA desenvolveu-se: Óleos e Gorduras (conversão do excesso de açúcar em gordura e suas consequências); Porções (quantidade de açúcar, sal e óleo em porções de alimentos industrializados); FLV (inclusão desses em preparações econômicas); e Exercício Físico (acúmulo de gordura com o sedentarismo). As equipes de saúde foram receptivas, mas houve dificuldades em uma pela ausência de momento exclusivo para a execução das oficinas que ocorriam junto ao atendimento da equipe devido à restrição de horário da médica, deixando os usuários dispersos pela atenção ao momento de serem chamados, menos coesos e participativos, e pouco frequentes. Entretanto, notou-se criação de vínculo com usuários e interesse nas oficinas, devido a abordagem participativa, a troca de conhecimentos, e a atividade lúdica, que também permitiram a construção do conhecimento sobre a importância da alimentação saudável e os riscos de hábitos alimentares inadequados. As intervenções tiveram boa aceitação e permitiu criação de vínculo melhorando a adesão e envolvimento nas atividades. Verifica-se a necessidade de continuidade de intervenções devido as mudanças de comportamento ocorrerem a longo prazo.
\end{abstract}

Descritores: Comportamento alimentar, Intervenção nutricional, Educação alimentar e nutricional 